\title{
PRIVATIZAÇÃO E MILITARIZAÇÃO: AMEAÇAS RENOVADAS À GESTÃO DEMOCRÁTICA DA ESCOLA PÚBLICA
}

A

privatização da educação é uma tendência política de alcance global. As medidas que favorecem essa privatização contam com forte presennos processos de reforma educacional em um número crescente de países, independentemente de seu nível de desenvolvimento econômico, tradição administrativa ou cultura política. Os seus efeitos, desafios e custos estão gerando debates tanto no campo acadêmico quanto no político, bem como nos mais diversos níveis, do local ao global.

Desde meados dos anos 1990, esse processo vem se consolidando no continente latino-americano e caribenho por meio de reformas educativas ancoradas em políticas de organismos multilaterais de cooperação e em plataformas de governos neoliberais para a educação, sempre com o suporte da grande mídia, que, não raro, pertence aos mesmos grupos empresariais que comercializam a educação.

São muitos os governos — ainda que alguns poucos tenham adotado posição contrária à privatização —, os meios de comunicação, as organizaçôes internacionais e as entidades empresariais que, atualmente, apoiam a crescente participação do setor privado nos sistemas educativos. Para esses agentes, a maior participação desse setor no campo da educação é garantia de eficiência (ou seja, a privatização entendida como forma rentável de ampliar a cobertura educativa), efetividade (o setor privado como fonte de melhora do rendimento escolar e de competitividade entre os provedores), diversificação (o setor privado como promotor do pluralismo desses sistemas) e inovação (o setor privado como incentivador de novas ideias educativas e de know how no setor público).

Contudo distintos segmentos da academia e da sociedade civil questionam com veemência essas suposiçôes e consideram que as políticas favoráveis à privatização educativa são, ao contrário, fonte de desigualdade educativa e de segregação escolar, sobretudo porque quando nos referimos à privatização educativa temos em mente um processo complexo e de variados matizes.

Diferentemente do que aconteceu em relação a outros serviços públicos, a privatização da educação não se realiza como transferência drástica da proprie-

DOI: 10.1590/ES0101-73302016v37n134ED 
dade das escolas (institutos ou universidades) das mãos do setor público para o setor privado. A privatização educativa é, mais bem, um processo que não costuma ocorrer de forma pura, mas pela constituição de sistemas educativos híbridos nos quais os setores público e privado interagem e partilham responsabilidades de modo complexo.

Em termos específicos, existem duas grandes medidas diante das quais se pode fazer interagir, de forma mais ou menos direta, o setor público com o privado no campo educativo. Por um lado, encontramos a liberalização da educação, permitindo ou mesmo incentivando que provedores privados surjam e expandam sua atividade no campo educativo. Por outro, há a introdução de normas, regras e mecanismos de mercado no mundo da educação, tais como a competitividade, a seleção ou os incentivos baseados em resultados.

Com base nesses dois tipos de política que, em grande medida, correspondem ao que Ball e Youdell (2007) denominam de, respectivamente, privatização exógena e privatização endógena, constituem-se os denominados quase-mercados educativos. Os quase-mercados diferem dos mercados puros na medida em que, ainda que os os primeiros introduzam mecanismos de mercado e elementos de competitividade nos serviços públicos, os preços do serviço são alterados em razão da intervenção estatal. As opções políticas para promover a competitividade no contexto dos quase-mercados educativos incluem, embora náo se restrinjam a elas, fórmulas competitivas de financiamento educativo, como os vouchers ou cheques escolares; a externalização de serviços educativos; a criação de centros financiados com recursos públicos, mas com gestâo privada (como as escolas charter e, no Brasil, as instituições conveniadas e as organizações sociais); ou ainda a publicação dos resultados escolares e a eliminação de eventuais limites organizativos, com objetivo de facilitar a eleição de escolas por famílias e estudantes. Referidas políticas andam, muitas vezes, de mãos dadas com outras intervençôes, como as avaliaçōes fundamentadas em provas estandartizadas e as políticas de accountability.

Mais recentemente, os quase-mercados e outras medidas de desenvolvimento do setor privado na educação foram introduzidos à força na agenda educativa global sob a etiqueta de alianças público-privadas (PPP) na educação. Essas parcerias definem-se como relaçóes contratuais entre o governo e o setor privado para a aquisição de serviços educativos por um período específico. Os referidos contratos podem se materializar em modalidades muito distintas, como a subcontratação de vagas em escolas privadas para crianças das classes populares, a gestáo privada de centros públicos ou fórmulas de financiamento educativo público que fomentam a escolha da escola, pública ou privada.

Outra tendência global relacionada à recente privatização educativa consiste na expansão das chamadas escolas privadas de baixo custo. Trata-se de um fenômeno contraintuitivo, já que a escola privada tem sido tradicionalmente uma opçáo para os mais ricos. Em contrapartida, estamos diante da emergência de uma tipologia de 
escolas privadas que, malgrados seus fins lucrativos, se supóem acessíveis, mesmo para as famílias mais desfavorecidas. O fenômeno é especialmente relevante na África Subsaariana, na Ásia Meridional e em alguns países latino-americanos, como o Peru.

Por fim, outra vertente da privatização em educação - ainda que de natureza totalmente diferente - consiste na maior participação de agentes privados (sobretudo grandes empresas) no financiamento de programas educativos por intermédio do que se conhece como filantropia ou responsabilidade social corporativa (RSC). Essa contribuição empresarial para a educação pode se dar de forma monetária, mas também como deslocamento de bens e serviços, capacitação para a docência, oferta de assessorias técnicas ou transferência de recursos humanos da própria empresa ao setor educativo público por certo período de tempo.

No caso brasileiro, há determinaçôes e imposiçóes de lógicas empresariais e gerenciais nos próprios fundamentos (ou princípios) e no funcionamento das políticas educacionais com a participação direta e efetiva do empresariado, como foi o caso do Plano de Desenvolvimento da Educação (PDE) e de sua principal medida, o Índice de Desenvolvimento da Educação Básica (Ideb). Organizaçôes e institutos empresariais vêm tendo influência crescente na proposição e condução de políticas educacionais nos governos de diversos partidos.

Uma tendência mais recente no Brasil são as organizaçôes sociais (OS) na educação. Vale lembrar que as OS, sem fins lucrativos, foram criadas no contexto do Plano Diretor da Reforma do Aparelho do Estado, de Bresser Pereira (Ministério de Administração e Reforma do Estado, em 1995), com a finalidade exclusiva de gerenciar instituiçôes públicas como hospitais, centros culturais, museus e escolas. Amplamente disseminadas nas demais áreas, nas quais acumulam problemas de transparência e de deficit de controle social, as OS começaram agora a ser testadas na educação básica.

Bresser, referenciando-se às premissas da Terceira Via, desenvolve a noção do público não estatal no processo de implementação e execução das políticas sociais, as quais incidem sobre diferentes esferas da sociedade. Para tanto, assegura-se que "a reforma do Estado deve ser entendida dentro do contexto da redefinição do papel do Estado, que deixa de ser o responsável direto pelo desenvolvimento econômico e social pela via da produçâo de bens e serviços, para se fortalecer na função de promotor e regulador desse desenvolvimento" (BRASIL, 1995, p. 12) ${ }^{1}$. No processo de "publicizaçáo", ocorre a "descentralização para o setor público não-estatal da execução de serviços que não envolvem o exercício do poder de Estado, mas devem ser subsidiados pelo Estado, como é o caso dos serviços de educação, saúde, cultura e pesquisa científica” (BRASIL, 1995, p. 18). Tal proposição contribuiu para intensificar os mecanismos e as crenças sobre a necessidade de transferência da execução de atividades do poder público estatal para o setor público não estatal, ou seja, a transferência de atividades não exclusivas do Estado, como educação, saúde, cultura, entre outros. 
Em consonância com os princípios neoliberais, em franca ascensão nos anos 1990, esse processo minimiza o papel do Estado como o principal executor das políticas sociais e fortalece a lógica de mercado nas políticas públicas, potencializando uma nova modalidade de privatização: o fornecimento público com gestão privada.

Entretanto é importante considerar historicamente que, antes da reforma de Estado promovida por Bresser Pereira, já se identificavam no início dos anos 1990 experiências de parcerias nos setores de educação e saúde, conforme resultados da pesquisa Novas Formas de Gestão dos Serviços Públicos: a Relação Público-Privada, de iniciativa da Fundação do Desenvolvimento Administrativo (Fundap), realizada em 1994.

Na primeira etapa da investigação, foram identificados nos estados de São Paulo e Paraná os seguintes casos: Microgestáo Privada, da Prefeitura de Maringá (1991-1992), em que a responsabilidade pela gestáo de todas as escolas municipais de primeiro grau e creches localizadas na zona urbana foi transferida, por licitação anual, para profissionais e funcionários do setor da educação, organizados em sociedades por cotas limitadas e/ou cooperativas de trabalhadores; Projeto Qualidade no Ensino, da Câmara Americana de Comércio (1990-1994), financiado por empresários ligados a esta instituição, através do qual foram adotadas três escolas de primeiro e segundo graus da rede estadual localizadas na regiáo do Embu, visando melhorar a qualidade de ensino pela promoção de avaliação externa do aprendizado dos alunos e pelo treinamento, orientaçáo e acompanhamento dos professores, além de apoio à elaboração de material pedagógico; Escola Padrão, da Caixa de Custeio (a partir de 1991), implantada pela Secretaria Estadual da Educação em cerca de 25\% da rede, com o objetivo de melhorar a qualidade de ensino dando autonomia de gestão às escolas, neste caso cabia à Caixa de Custeio gerenciar os recursos advindos às escolas por auxílios e contribuiçóes de pessoas de direito público e privado; Adoção de Escolas Públicas (a partir de 1990), projeto implementado por convênios, contratos ou acordos verbais firmados entre cerca de 50 diretores de escolas públicas estaduais e empresas, que passariam a contribuir voluntariamente para a melhoria dos padróes físico e pedagógico das respectivas escolas adotadas.

O estudo dos referidos casos permitiu à equipe de pesquisadores contextualizar as novas formas de gestáo e examinar a incidência dos fatores internacionais, das novas realidades econômica e tecnológica e da crise gerencial da administração pública anunciada naquele contexto. Com base nos resultados da análise, pôde-se avançar no desenvolvimento dos conceitos de parceria público-privada e na construçáo de "tipologias das formas jurídico-institucionais" capazes de apreender as novas modalidades de gestão dos serviços públicos, o papel do Estado nessas novas modalidades de gestão que aglutinavam características essenciais da gestão pública e da gestấo privada (FUNDAP, 1997).

Acirra-se hoje a lógica dos quase-mercados, que põe em evidência o caráter híbrido das novas formas de financiamento, fornecimento e regulação que 
o próprio Estado incentiva e que se inscreve na redefinição das suas funçôes. Isso promove, no interior de seu espaço estrutural, pressōes competitivas entre serviços, a partir da adoção de instrumentos e princípios de gestấo baseados na racionalidade instrumental que subordinam os direitos sociais às lógicas da eficácia e da eficiência (JANELA, 2001). Tal lógica reverbera, na realidade brasileira, mediante diferentes formatos.

Nesses termos, é expressiva a experiência em curso no estado de Goiás, com a decisão de transferir a gestão de escolas estaduais para OS. Segundo a proposta goiana, o Estado repassará recursos para a manutençáo das escolas e espera obter em troca a melhoria do desempenho dos estudantes nas avaliaçóes externas. Uma mudança de grande significação é a liberdade que se dará às OS para contratar e demitir professores e funcionários, o que de imediato compromete a liberdade pedagógica desses educadores e tenderá a destruir a carreira docente à medida que esses professores, com contratos precários, venham a substituir os docentes concursados.

Considerando uma conjunçáo de fatores, como os interesses privados em acessar fundos públicos, a ideologia da privatização endógena, o interesse em desmobilizar a categoria docente e os limites de folha salarial impostos aos governos pela Lei de Responsabilidade Fiscal, é largo o campo para a proliferação das OS na educação, o que torna o debate sobre as consequências da privatização da educação ainda mais urgente.

Nesse mesmo quadro se explica a recente tentativa de reforma do ensino público paulista, denominada oficialmente como Reorganizaçáo Escolar, medida não implementada em 2016 em razão da forte oposição de estudantes, educadores e pesquisadores, a qual foi precedida pelo Programa Educação: Compromisso de São Paulo, iniciado em 2011. Conforme mostrou o Observatório da Educação da Ação Educativa, há um modus operandi na produção de políticas educacionais no Estado caracterizado pela baixa institucionalidade das parcerias com o empresariado e pela oferta de consultorias privadas - nesse caso, a consultoria McKinsey - cujos resultados não são tornados públicos. Ao mesmo tempo, pouquíssima atenção dá-se à participação social institucionalizada em conferências e conselhos².

Embora de natureza política distinta, encontram-se em curso outras medidas questionáveis no corpo das políticas de terceirização da gestấo da escola pública. Uma das mais preocupantes é tocante à Polícia Militar (PM) ou ao Corpo de Bombeiros Militar, que assumiram, em vários estados brasileiros, a administraçáo de escolas públicas, principalmente daquelas em áreas de grande risco social. É o que está ocorrendo, por exemplo, mesmo sob os protestos de educadores e entidades de educação e, em alguns casos, da população local, em Goiás, Sergipe, Bahia, Ceará, Piauí, Amazonas, Tocantins, Minas Gerais, Distrito Federal e Rio de Janeiro, onde o Colégio Dom Pedro II está sob o co- 
mando e a responsabilidade do Corpo de Bombeiros Militar. Estima-se que, no total, haveria hoje mais de 100 escolas sob gestão militar no Brasil ${ }^{3}$.

A transformação das escolas públicas de educação básica em colégios militares e a defesa da gestão educacional militarizada conduzida pela PM como solução dos problemas da educação pública expressam o retrocesso social em curso no país. As diversas inconstitucionalidades e ilegalidades identificadas, como a cobrança indevida de taxas escolares e de militares sem qualquer formação pedagógica exercendo a direção de escolas e a orientação pedagógica, são consequências do grande equívoco político, pedagógico e social; significa declarar a inviabilizaçáo da gestấo educacional democrática, consagrada na Lei das Diretrizes e Bases da Educação Nacional — LDB (Lei 9.394 de 1996)e na Meta 19 do Plano NACIONAL de Educação - PNE (Lei 13.005, de 2114), que trata da Gestáo Democrática da Educação, transformando-a em uma questão de segurança e controle.

A forte ingerência empresarial na educação pública hoje contribui para aumentar a ação da escola enquanto reprodutora das desigualdades e hierarquias sociais existentes, no entanto, o processo educacional não é monolítico. Constitui, ao contrário, uma relação entre sujeitos sociais, e, dessa maneira, sempre podem ocorrer resistências e o surgimento eventual da crítica e da contestação. $O$ mundo é maior do que a escola e a prática social de professores e alunos - crianças, adolescentes, jovens e adultos - mais ampla, rica e contraditória. É o que nos mostrou, recentemente, o movimento dos estudantes do ensino médio contra o projeto autoritário de reorganizaçáo das escolas públicas estaduais em São Paulo. É o que nos mostram atualmente os estudantes e educadores goianos e de outros estados, que resistem à transferência da gestâo escolar para OS ou à militarização das escolas.

A superação do quadro adverso da educação pública e do avanço predatório da privatização, sob suas diferentes formas, depende dos rumos assumidos pelas políticas públicas, isto é, do avanço das forças sociais empenhadas na promoção de políticas públicas democráticas, de caráter permanente, de políticas de Estado capazes de consolidar o acesso e a permanência de todos os brasileiros na escola pública, laica, gratuita, de gestão pública e de qualidade social referenciada. Ela passa, sobretudo, pelo fortalecimento da gestáo democrática e transparente da educação, caminho oposto ao da privatização das decisóes educacionais e da gestão de escolas, medidas que tendem a destruir gradativamente as capacidades de educadores e gestores educacionais. Em resumo, depende de nós, sujeitos da educação, e da capacidade organizativa que conseguirmos construir e mobilizar.

A produção de estudos e diagnósticos, que necessita intensificar-se e expandir-se, é etapa importante na luta resistente. O conjunto de pesquisas aqui apresentado pretende contribuir para o esforço coletivo de superação da tendencial privatização da educação no Brasil e no continente latino-americano e caribenho.

Editores da Revista Educação \& Sociedade 


\section{Notas}

1. Ver: A nova gestão pública. Educação e Sociedade, Campinas, v. 36, n. 132, jul.-set., 2015.

2. O relatório produzido está disponível em: <http://www.acaoeducativa.org.br/index.php/ educacao/47-observatorio-da-educacao/10004523-observatorio-divulga-levantamento-sobre-programa-educacao-compromisso-de-sao-paulo >. Acesso em 14 de fevereiro de 2016.

3. Ver: <http://oglobo.globo.com/sociedade/policia-assume-escola-em-area-violenta-demanaus-impoe-rotina-militar-16590532\#ixzz3fzgBPaOf $>$ e $<$ http://www1.folha.uol.com.br/ educacao/2014/01/1399354-pm-assume-mais-escolas-em-goias-em-meio-a-polemica-sobre-cobranca.shtml>. Acesso em: ago. 2015.

\section{Referências}

BALL, S.; YOUDELL, D. Privatización encubierta en la educación pública. In: Congreso Mundial Internacional de la Educación, 5., 2007. Anais... Disponível em: < http://firgoa. usc.es/drupal/files/2007-00242-01-S.pdf>. Acesso em: fev. 2016.

BRASIL. Presidência da República. Plano Diretor da Reforma do Aparelho do Estado. Brasília: Presidência da República, Câmara da Reforma do Estado, Ministério da Administração Federal e Reforma do Estado, 1995.

FUNDAÇÃO DO DESENVOLVIMENTO ADMINISTRATIVO (Fundap). Novas formas de gestâo dos serviços públicos: a relação público-privada. Direção do projeto: Laércio F. Betiol. Coordenação do projeto: Maria Cristina Costa Pinto Galvão. São Paulo, 1997.

JANELA, A. A. Reforma do Estado e políticas educacionais: entre a crise do estado-nação e a emergência da regulação supranacional. Educação e Sociedade, v. 22, n. 75, p. 15-32, set. 2001. 